\title{
ADJETIVOS DE CARÁTER OPOSITIVO NA FORMAÇÃO DE TERMOS SINTAGMÁTICOS DA ECONOMIA
}

\author{
Ieda Maria Alves*
}

\begin{abstract}
Resumé : Ce travail a le but d'étudier un aspect de la nomination en Terminologie, en mettant de l'emphase sur un processus de formation employé dans toutes les langues de spécialité: les termes syntagmatiques. Ce procédé, qui présente beaucoup d'autres dénominations, peut être représenté par de différentes structures, dans lesquelles l'adjectif joue souvent un rôle important. Dans ce texte, nous nous dédions à l'étude du rôle joué par les adjectifs qui marquent l'opposition dans la formation de termes syntagmatiques (nom + adjectif) de la terminologie de l'Economie.
\end{abstract}

Palavras-chave: terminologie, adjectif, rapports d'opposition, néologie, économie.

\section{INTRODUÇÃO}

O processo de nomeação, em uma ciência, marca seu nascimento e seu desenvolvimento e também o de sua terminologia. Esta relação entre nomeação e o desenvolvimento de uma terminologia tem sido manifestada por estudiosos de diferentes tendências.

Benveniste, em "Genèse du terme "“scientifique" (Problèmes de linguistique générale), enfatiza o papel da denominação em uma ciência:

A constituição de uma terminologia própria marca, em toda ciência, o início ou o desenvolvimento de de uma conceptualização nova, e isso faz com que ela assinale um momento decisivo de sua história. Poder-se-ia mesmo dizer que a própria história de uma ciência se resume na de seus termos. Uma ciência somente começa a existir ou impor-se na medida em que ela impõe seus conceitos por meio de suas denominações. Ela não tem outro meio de impor sua legitimidade se não especificar seu objeto por meio de sua denominação, objeto esse que pode ser uma ordem de fenômenos, um domínio novo ou um modo novo de relação entre determinados dados. A aparelhagem mental consiste primeiramente em um inventário de termos que registram, configuram ou analisam a realidade. Denominar, isto é, criar um conceito, é a operação ao mesmo tempo primeira e última de uma ciência. ${ }^{1}$ (Benveniste, 1974, vol. 2, p. 247)

\footnotetext{
${ }^{*}$ Professora titutlar da Universidade de São Paulo (USP). Coordenadora do Observatório de Neologismos Científicos e Técnicos do Português Contemporâneo.

${ }^{1} \mathrm{La}$ constitution d'une terminologie propre marque dans toute science l'avènement ou le développement d'une conceptualisation nouvelle, et par là elle signale un moment décisif de son histoire. On Professora titutlar da Universidade de São Paulo. Coordenadora do Observatório de Neologismos Científicos e Técnicos do Português Contemporâneo pourrait même dire que l'histoire propre d'une science se résume en celle de ses termes propres. Une science ne commence d'exister ou ne peut s'imposer que dans la mesure où elle fait exister et où elle impose ses concepts dans leur dénomination. Elle n’a pas d'autre moyen d'établir sa légitimité que de spécifier en le dénommant son objet, celui-ci pouvant être un ordre de phénomènes, un domaine nouveau ou un mode nouveau de relation entre certaines données. L'outillage mental consiste d'abord en un inventaire de termes qui recensent, configurent ou analysent la réalité. Dénommer, c'est-à-dire créer un concept, est l'opération en même temps première et dernière d'une science.
} 
De maneira análoga, Rey, em Essays on terminology, ressalta também a relação entre Terminologia e o processo da nomeação: "A Terminologia refere-se, fundamentalmente, a nomes e ao processo de nomeação"2 (REY, 1995, p. 11).

Cabré, em La terminología. Teoría, metodología, aplicaciones reitera esta relação e enfatiza a criação neológica permanente nas línguas de especialidade:

O aparecimento de um novo conceito leva, normalmente, ao aparecimento de uma nova denominação. E essa nova forma designativa nasce em um determinado sistema linguístico, próprio da sociedade que criou o novo conceito. A neologia, concebida como uma atividade de criação de novas denominações é, evidentemente, necessária nos domínios de especialidade em que o aparecimento constante de novos conceitos requer uma atividade neológica permanente.3 (CABRÉ, 1993, p. 443)

Neste trabalho, vamos enfocar um aspecto da denominação em Terminologia, enfatizando o emprego adjetival em um processo de formação observado em todas as línguas de especialidade: os termos sintagmáticos. Esse tipo de formação, que conhece muitas outras designações, conforme assinala Kocourek (1991), é representado por diferentes estruturas - substantivo + adjetivo, substantivo + preposição + substantivo, especialmente -, que, por sua vez, podem ser expandidas: substantivo + adjetivo + adjetivo, substantivo + adjetivo + preposição + substantivo, substantivo + preposição + substantivo + adjetivo... Estudaremos, especificamente, o papel desempenhado pelas relações semânticas opositivas (também denominadas polares) expressas por alguns adjetivos na formação dos termos sintagmáticos que apresentam a estrutura substantivo + adjetivo.

\section{AS RELAÇÕES DE OPOSIÇÃO}

A formação de termos sintagmáticos nas diferentes terminologias implica, não raro, o recurso a relações semânticas de caráter similar ou opositivo.

Aspectos da sinonímia nas línguas de especialidade têm sido enfocados em diferentes estudos, a exemplo dos trabalhos de Alves (1994), Contente (2008), Araujo (2007), entre vários outros. As relações opositivas, menos estudadas que as sinonímicas, implicam também uma relação de semelhança entre termos, pois opostos sempre apresentam, ao menos, um sema comum. Sobre esta relação, lemos em Niklas-Salmien:

Ela /a antonímia/ aparece, de um certo modo, como o contrário da sinonímia. "Antônimo" é o antônimo de "sinônimo". Ela designa uma relação entre dois termos de sentidos contrários. Deve-se enfatizar que as palavras em oposição devem ter em comum alguns traços que permitem colocá-las em relação de modo pertinente.4 (NIKLAS-SALMIEN, 1997, p. 113)

De acordo com Varo Varo (2007), as relações de oposição são observadas e descritas por autores desde a Antiguidade clássica. Princípios teóricos baseados na existência de opostos são encontrados nas teorias cosmológicas dos filósofos pré-socráticos. Segundo a Autora, Aristóteles atribuía a

\footnotetext{
${ }^{2}$ Terminology is fundamentally concerned with names and the process of naming.

${ }^{3}$ La aparición de un nuevo concepto conlleva normalmente la aparición de una nueva denominación. Y esta nueva forma designativa nace en un determinado sistema lingüístico, el proprio de la sociedad que ha creado el nuevo concepto. La neología, concebida como una actividad de creación de nuevas denominaciones, es evidentemente necesaria en los dominios de especialidad donde la aparición constante de nuevos conceptos requiere una actividad neológica permanente.

${ }^{4}$ Elle / 1'antonymie/ apparaît d'une certaine façon comme le contraire de la synonymie. « Antonyme » est l'antonyme de « synonyme ». Elle désigne une relation entre deux termes de sens contraires. Il importe de souligner que les mots mis en opposition doivent avoir en commun quelques traits qui permettent de les mettre en relation de façon pertinente.
} 
Alcmeão, filósofo pré-socrático, a doutrina de que "a maior parte das coisas humanas andam aos pares"

Seguindo Lehmann e Martin-Berthet (1998, p. 59), podemos considerar que a relação de oposição une duas palavras da mesma classe gramatical que têm em comum uma parte de seus sememas.

Lyons (1978, p. 219) coloca a questão da categorização da experiência em termos binários contrastivos, e, sem pretensão de responder ao problema, pergunta-se se ela reflete na linguagem uma tendência geral, como uma causa condicionando seu efeito, ou, ao contrário, é a pré-existência de unidades lexicais opostas na linguagem que nos leva a dicotomizar, ou polarizar, nossos julgamentos e nossas experiências. Qualquer que seja a resposta, Lyons conclui que o princípio da oposição binária é essencial ao funcionamento das línguas naturais.

Se tomarmos como referência a classificação do Autor (op. cit., p. 212-227), a oposição de significado expressa-se de três formas:

- por complementaridade, ou impossibilidade de gradação, a exemplo de vivo / morto, macho / fêmea, em que a negação de um implica a afirmação de outro, de modo que os dois não podem ser negados simultaneamente: "Paulo está vivo implica que ele não está morto";

- por antonímia, como rico / pobre, grande / pequeno, em que se verifica uma gradação muito, pouco, relativamente rico ou pobre - que permite uma comparação e a suposição da existência de graus intermediários: "Paulo é mais rico do que Mário". Diferentemente do que ocorre com os opostos por complementaridade, a negação de um não implica a afirmação do outro, pois dizer que "Paulo não é rico" não implica afirmar que "Paulo é pobre";

- por conversão ou reciprocidade, como marido / mulher, pai / filho, em que se observa uma relação recíproca: "Paulo é o pai de Mário" implica que "Mário é o filho de Paulo".

Além dessas oposições apresentadas por Lyons, outras possibilidades opositivas têm sido apontadas. Niklas-Salmien (1997) refere-se a termos incompatíveis, observados em conjuntos constituídos por vários elementos, como os nomes das cores, dos dias da semana, dos meses e das estações do ano.

A expressão da oposição, nos termos sintagmáticos, é manifestada prioritariamente pela classe dos adjetivos, revelando, assim, a importância dessa classe, de maneira geral ainda pouco estudada nos trabalhos terminológicos, na formação dos termos. Apesar dessa pouca atenção dada aos adjetivos na formação de unidades lexicais terminológicas, a importância da classe dos adjetivos na expressão da oposição é enfatizada por autores citados por Geckeler:

O que tradicionalmente se entende por "antonímia" aparece ocasionalmente em trabalhos recentes com a nova denominação de "polaridade". Nesses trabalhos se enfatiza frequentemente que a polaridade é, precisamente, uma característica do adjetivo. Assim, H. Brinkmann escreve o seguinte: "No fundo as relações léxicas bilaterais se dão em todas as classes de palavras: nós as encontramos na orientação espacial e temporal, no mundo do existente (concebido conceptualmente no substantivo), no domínio de uma ação (no verbo) e na soma de posição do homem (no adjetivo). Porém somente ao adjetivo pertence a bilateralidade dos traços essenciais da classe de palavra...O mundo do adjetivo está atravessado por séries polares". Brinkmann chega, inclusive, a afirmar que a polaridade representa "o princípio de ordenação no mundo adjetivo". Este conceito teve também aceitação na gramática do Duden ( $\$ 841$ ). M. Bierwisch investigou a estruturação dos adjetivos alemães do espaço com ajuda do conceito de "polaridade"6. (GECKELER, 1976, p. 294-295)

\footnotetext{
$5 / . . /$ la mayoría de las cosas humanas van en parejas.

${ }^{6}$ Lo que tradicionalmente se entiende por "antonimia" aparece ocasionalmente en trabajos recientes bajo la nueva etiqueta de "polaridad". En ellos se subraya muy a menudo que la polaridad es característica precisamente del adjetivo. Así, H. Brinkmann escribe lo seguiente: "En el fondo las relaciones léxicas bilaterales se dan en todas las clases de palabras: nos las encontramos en la orientación espacial y temporal, en el mundo de lo existente (concebido conceptualmente en el sustantivo), en el dominio de tal acción (en el verbo) y en la soma de posición del hombre (en el adjetivo). Pero sólo en el adjetivo pertenece la bilateralidad a los rasgos esenciales de la clase de palabra...El mundo del adjetivo está atravesado por series polares". Brinkmann llega incluso a afirmar que la polaridad
} 
Essas relações opositivas, observadas desde a Antiguidade clássica e mencionadas por autores de diferentes tendências, transparecem na formação de termos nas áreas de especialidade.

\section{$O$ CORPUS DE ANÁLISE}

Neste trabalho, analisamos a formação de termos sintagmáticos da Economia que apresentam a estrutura substantivo + adjetivo, em que se verifica a presença de relações opositivas expressas por adjetivos.

Esses termos são extraídos de um corpus representado por materiais de divulgação, a Base de Termos da Economia (6 200 termos, cada um com uma ou mais ocorrências), que constitui um corpus de divulgação baseado em cadernos de Economia de jornais brasileiros de grande circulação Folha de S. Paulo (FSP), O Globo (G) e $O$ Estado de S. Paulo (ESP) -, no jornal especializado Gazeta Mercantil (GM), em duas revistas semiespecializadas em Economia - Conjuntura Econômica (CE) e Exame (E) - e em documentos divulgativos de instituições bancárias.

Esse corpus de divulgação é complementado por um outro de caráter técnico-científico, a Base de Termos Especializados da Economia (5 866 termos, cada um com uma ou mais ocorrências), que representa um corpus constituído por manuais, teses e artigos de periódicos relativos à Economia. Por oposição ao corpus de divulgação, consideramos esse corpus como sendo de caráter especializado.

Esses dois corpora foram coletados no âmbito do Projeto TermNeo (Observatório de Neologismos do Português Brasileiro Contemporâneo).

Os dados integrantes dessas bases constituem, sobretudo, termos sintagmáticos e, dentre esses, a maioria apresenta a estrutura substantivo + adjetivo. Assim, em um conjunto de 6200 termos do corpus de divulgação, 3913 constituem termos sintagmáticos e, dentre esses, 1440 apresentam a estrutura substantivo + adjetivo. O corpus especializado apresenta 4478 termos sintagmáticos, dentre os quais 1713 são formados por um sintagma de estrutura substantivo + adjetivo.

Nem todos os termos sintagmáticos que apresentamos são neológicos, se tomarmos por referência o uso desses termos na área da Economia ou sua inserção em dicionários dessa língua de especialidade. No entanto, os adjetivos que integram esses sintagmas representam, sobretudo, a possibilidade de integração a novos sintagmas, formando novas unidades lexicais dessa terminologia, bastante dinâmica e criativa.

\section{AS RELAÇÕES DE OPOSIÇÃO NA FORMAÇÃO DE TERMOS NA ÁREA DA ECONOMIA}

A observação de termos da área da Economia revela que as relações de oposição podem ser observadas na formação de termos simples e complexos.

Termos simples representativos das classes variáveis revelam relações opositivas, a exemplo de liquidez / iliquidez, poupança / despoupança (substantivos), líquido / bruto, fixo / variável (adjetivos), comprar / vender (verbos). São os termos sintagmáticos, no entanto, que mais frequentemente expressam relações opositivas, que, não raro, resultam de um processo de expansão a partir de um termo genérico.

representa "el principio de ordenación en el mundo adjetivo". Este concepto ha tenido aceptación también en la gramática del Duden (§ 841). M. Bierwisch investigó la estructuración de los adjetivos alemanes del espacio con ayuda del concepto de "polaridad". 
Lyons, como já salientamos, reserva os termos antonímia e antônimo aos opostos graduáveis. Explica esse fato por considerar que são os opostos graduáveis os que manifestam a propriedade de polaridade da maneira mais evidente (1978, p. 226).

Os adjetivos são, comumente, classificados em qualificativos e classificadores (cf. NEVES, 2000, p. 184-219). Os classificadores são também chamados de relacionais, que, do ponto de vista morfológico, são os adjetivos derivados de um substantivo comum (presidencial, derivado de presidente) ou próprio (brasileiro, derivado de Brasil) (cf. MÉLIS-PUCHULU, 1991, apud FRADIN, 2008, p. 71). Bosque (1999, p. 138) atribui a esses adjetivos a "capacidade de fazerem parte de sistemas binários e serem termos de correlações de polaridade"7.

Os adjetivos antonímicos observados nos termos sintagmáticos analisados correspondem, sobretudo, a adjetivos qualificadores ou qualificativos, que indicam uma propriedade que nem sempre corresponde a uma característica própria dos substantivos a que eles se referem, o que pode revestir-se de uma certa vaguidade. São adjetivos predicativos, que predicam, ou seja, atribuem uma característica ao substantivo que acompanham. Neves (op.cit., p. 184-185) inclui entre os adjetivos qualificadores os adjetivos formados com prefixos negativos e os terminados com sufixos que formam adjetivos derivados de verbos (-do, -to e -nte). São passíveis de serem graduados e intensificados.

Diferentemente dos adjetivos qualificadores, continua a Autora, os adjetivos classificadores ou classificatórios são denominativos e não qualificam o substantivo, não atribuem a ele uma propriedade que nem sempre é intrínseca. Geralmente correspondem a sintagmas nominais do tipo de + nome. Exemplos citados pela Autora: sistemas DIGESTIVO (de digestão); RESPIRATÓRIO (de respiração); DE TRANSPORTE; EXCRETOR (de excreção). Do ponto de vista semântico, os adjetivos classificadores não apresentam um caráter vago (idem, p. 192).

Adjetivos que marcam oposição, sobretudo os qualificativos, formam termos sintagmáticos que revelam diferentes possibilidades, intrínsecas às características da terminologia da Economia.

Uma dessas possibilidades refere-se à diversidade de ganhos proporcionados pelas aplicações, pelos salários, pelo câmbio. Assim, ao caráter fixo de uma aplicação, de um ganho, de um rendimento, já anteriormente determinado e, portanto, livre de possíveis perdas, opõe-se o caráter variável, que implica a possibilidade de lucros mais ambiciosos, mas também aponta para perdas eventuais, não previsíveis. Esses dois adjetivos têm formado numerosos termos sintagmáticos, a exemplo de câmbio fixo / câmbio variável, renda fixa / renda variável, rendimento fixo / rendimento variável... Contextualizamos a dicotomia renda fixa / renda variável, que representa a possibilidade de aplicação com lucros pré-estabelecidos (renda fixa) ou os lucros potencialmente maiores, como os provenientes das aplicações em bolsas e derivativos, porém incertos e que por vezes acarretam perdas para o investidor (renda variável):

O cálculo da Maneo baseia-se na carteira média dos fundos de pensão: eles aplicam $70 \%$ do capital em $<$ renda fixa $>$ e $30 \%$ em <renda variável $>$. Os investimentos feitos em <renda variável $>$ estão sofrendo perdas este ano, já que os fundos costumam seguir o Ibovespa (Índice da Bolsa de Valores de São Paulo), que caía 14,97\%, na última sexta-feira. Já as aplicações em <renda fixa> estão rendendo $14,61 \%$, correspondentes à variação do CDI). (FSP, 06-11-00)

O caráter graduável de fixo por oposição a variável manifesta-se em um contexto do corpus especializado, em que se verifica que um insumo, denominado insumo fixo por oposição a insumo variável, não é sempre absolutamente fixo:

Portanto, um <insumo fixo> é definido como aquele cuja quantidade não pode prontamente ser mudado quando as condições de mercado indicam que uma variação imediata no produto é desejável. Pode-se estar seguro de que nenhum insumo é sempre absolutamente fixo, não importando quão pequeno é o período de tempo em consideração. /.../

${ }^{7} / \ldots /$ su capacidad para formar parte de sistemas binarios y ser por tanto términos de correlaciones de polaridad. 
$<$ Insumo variável>, por outro lado, é o insumo cuja quantidade pode variar quase instantaneamente em resposta às desejadas variações na quantidade de produção. Muitos tipos de mão-de-obra, de insumos naturais e matérias-primas processadas caem nesta categoria. (FERGUSON, 1994, p. 147)

Outra oposição que caracteriza a terminologia da Economia concerne ao caráter dicotômico entre os adjetivos bruto e líquido (ganho bruto / ganho líquido, juro bruto / juro líquido, rendimento bruto / rendimento líquido, valor bruto / valor líquido), que implicam a diferença entre um valor sem descontos, sem dedução de encargos, e o valor resultante dessa dedução, respectivamente, conforme ilustram os exemplos de lucro bruto / lucro líquido extraídos do jornal econômico Gazeta Mercantil e de um manual de Economia:

O <lucro bruto> da rede, no segundo trimestre, totalizou $\mathrm{R} \$ 906,8$ milhões, com crescimento de $18,9 \%$ em relação ao mesmo período do ano passado. Já o <lucro líquido> foi de R $\$ 58,2$ milhões e aumentou 2,6\%. (GM, 29-07-04)

O que se denomina <lucro bruto> muitas vezes engloba não somente esse excedente, mas também o que é retido para compensar tais perdas extraordinárias. Os juros que o tomador de empréstimo pode permitir-se pagar são proporcionais somente ao <lucro líquido>. (SMITH, 1983, p. 115)

As altas taxas de inflação que o Brasil sofreu até o início da década de 90 possibilitaram o uso frequente dos adjetivos opositivos nominal / real, que estabelecem algumas relações com bruto / líquido. De maneira análoga a bruto, o adjetivo nominal também se refere a um valor sem descontos; diferentemente, porém, implica um valor sem desvalorização de moeda, sem efeitos causados pela inflação. Líquido e real têm em comum o valor a que realmente se referem: o primeiro, após os descontos de encargos e despesas e, o segundo, após as perdas acarretadas pelos efeitos inflacionários.

Real e nominal formam vários termos sintagmáticos, que opõem os salários (salário nominal / salário real), os ganhos (ganho nominal / ganho real), os lucros (lucro nominal / lucro real), as rendas (renda nominal / renda real), os rendimentos (rendimento nominal / rendimento real) e também as perdas (perda nominal / perda real) e os déficits (déficit nominal / déficit real). Ilustramos o emprego desses adjetivos com um contexto do economista Bacha, que põe em evidência a busca de um aumento real para o salário nominal:

Tal fenômeno parece ter ocorrido em países como Suécia e Inglaterra, onde os sindicatos têm condições de, através da política de pressão salarial, reduzir a margem de lucros e, portanto, aumentar o <salário real $>$, porque, à medida que as indústrias suecas e inglesas aumentam os seus preços para compensar o aumento dos custos, elas se vêem invadidas por produtos alemães em seu próprio país e em terceiros mercados.

Neste caso, dada a competição intercapitalista, tem-se a possibilidade de que setores trabalhistas, atuando separadamente, possam transformar um aumento de <salário nominal $>$ em aumento real, mas isso depende de condições específicas. (BACHA, 1989, p. 120)

Outra oposição recorrente em textos da área da Economia refere-se à diferença entre o que tem caráter público e o que tem caráter privado. Esses adjetivos marcam uma diferente perspectiva que, para Gasparini (2002, apud Mafra Filho), está baseada no interesse. O jurista aborda a questão dos dois ramos (Direito Público e Direito Privado) do Direito, tratando-os como uma unidade indivisível, porém lembra a sua divisão em privado e público, já existente no Direito Romano: "o Direito Público regularia as relações jurídicas em que predomina o interesse do Estado, ao ponto que o Direito Privado disciplinaria as relações jurídicas em que predomina o interesse dos particulares. $\mathrm{O}$ critério do interesse é que dividiria, assim, o Direito em dois ramos".

Assim, caracteriza-se como público tudo que é relativo ao governo de um país, sendo privado o que diz respeito ao que não é governamental, o que é relativo aos particulares. A oposição entre esses 
dois adjetivos marca diferentes termos da Economia, como bem público / bem privado, capital público / capital privado, crédito público / crédito privado, gasto público / gasto privado, investimento público / investimento privado, setor público / setor privado, dentre muitos outros.

Exemplificamos essa oposição com os termos opostos título público e título privado, cujos contextos definitórios ilustram o que esses termos representam:

\section{<TÍTULOS PÚBLICOS>}

Definição [São papéis emitidos pelo governo para captar recursos e financiar suas dívidas. (FSP, 16-0701)

$<$ Título privado>

Emitido por empresas ou instituições financeiras privadas ou mesmo controladas por Estados (caso das caixas econômicas e do Banco do Brasil). (FSP, 08-11-97)

O caráter total ou parcial de um todo é, também, uma característica que se reflete na formação de termos sintagmáticos. O caráter parcial se opõe a três adjetivos, geral, pleno e total, embora esses três adjetivos não sejam intercambiáveis em todas as formações. Desse modo, equivalência salarial parcial, que representa uma parte em relação a um todo, opõe-se a equivalência salarial plena (e, neste caso, poderíamos ter a denominação sinonímica equivalência salarial total):

$<$ Equivalência salarial parcial $>$ - É o sistema de reajuste pelo qual as prestações são corrigidas um ou dois meses após a data-base profissional do mutuário. Há só um reajuste por ano. /.../ < Equivalência salarial plena> - É o sistema de reajuste pelo qual as prestações são corrigidas um ou dois meses após as antecipações salariais ou a data-base (época do dissídio) do mutuário. (FSP, 01-09-91)

A oposição entre o parcial e o total transparece em alguns termos sintagmáticos, a exemplo de indexação parcial / indexação total, em que total tem o mesmo valor semântico do adjetivo pleno:

Uma possibilidade é a <indexação parcial>: reajustam-se os salários nominais em intervalos constantes de tempo, por uma fração da taxa de inflação decorrida (80\%, por exemplo). Esse sistema foi tentado no Brasil em 1983 pelo Decreto-Lei 2.045, mas o Congresso derrubou-o. Em seu lugar, promulgou-se o Decreto-Lei 2.065, que estabelecia <indexação total> para os salários mais baixos e parcial para os mais altos, um esquema pouco eficiente, que não conseguiu baixar a inflação e provocou algumas sérias distorções na pirâmide salarial. (SIMONSEN; CYSNE, 1989, p. 439)

Já o caráter parcial denotado pelo termo equilíbrio parcial opõe-se a uma aplicabilidade à totalidade ou à maioria de um conjunto de coisas, expressa por equilíbrio geral. Esses termos são observados no corpus especializado:

O Caso de n Mercadorias. A discussão acima do modelo de mais de uma mercadoria limitou-se ao caso de dois bens. No entanto, deve ficar claro que já estamos saindo da análise de <equilíbrio parcial> e ingressando no reino do <equilíbrio geral>. (CHIANG, 1982, p. 48)

O conceito de localização no espaço e no tempo transparece também na formação de termos sintagmáticos opostos.

A relação espacial manifesta-se por meio da oposição entre os adjetivos vertical e horizontal, termos da Geometria denotadores de espacialidade. A oposição marcada entre esse adjetivos refere-se a duas diferentes posições, uma em relação à outra: assim, o que é vertical está em situação perpendicular ao que está em posição horizontal e, de maneira contrária, o que está em posição horizontal, paralelamente à linha do horizonte, encontra-se em situação perpendicular ao que está em posição vertical. 
Os termos equidade horizontal e equidade vertical, empregados na terminologia da Economia, marcam uma oposição entre o que é igual, expresso por horizontal, e o que é diferente, que se manifesta por meio do determinante vertical, conforme podemos verificar em um contexto de Riani:

Por um lado, a <equidade horizontal > significa que os indivíduos com iguais habilidades devem pagar o mesmo montante de tributos.

/.../ a <equidade vertical> requer que indivíduos com diferentes habilidades paguem tributos em montantes diferenciados. (RIANI, 1990, p. 104)

A noção de temporalidade, anterior ou posterior ao momento presente, é também marcada na terminologia da Economia e representada por prefixos opostos que se antepõem a uma mesma base e integram dois termos sintagmáticos que se diferenciam pelo caráter temporal. Assim, a oposição temporal pré- / pós- transparece, no corpus de divulgação, para expressar a anterioridade e a posterioridade em relação a um fato.

Exemplificamos com os adjetivos pré-pago e pós-pago, que determinam diferentes substantivos ligados, especialmente, à telefonia (celulares, contas, cartões, planos, serviços...):

Ainda segundo o termo, a Oi dará descontos para os 3.196.590 usuários do <serviço pré-pago>, 25.962 consumidores de telefonia fixa, 11.974 usuários do serviço de banda larga, 4.731 usuários do 'OI conta total' e 194.990 clientes do <serviço pós-pago>. (http://www1.folha.uol.com.br)

No corpus que estudamos, podemos observar que, além da oposição de cunho heteronímico, a antonímia em adjetivos da terminologia da Economia é também manifestada, morfologicamente, por meio de prefixos de caráter opositivo que, associados a uma mesma base, estabelecem a oposição entre dois termos sintagmáticos.

Essa oposição é manifestada, como mostramos acima, entre os prefixos pré- e pós- e também por outros prefixos. Os prefixos in- e ex-, designativos de "movimento para fora" e "movimento para dentro", respectivamente, opõem-se nas formações já originárias do latim interno / externo.

Os pares interno / externo compõem termos que representam tendências da Economia, mais complementares do que opostas, voltadas para o próprio país, mas também buscando inserções no contexto internacional. Formam-se, assim, termos como crédito interno / crédito externo, déficit interno / déficit externo, investidor interno / investidor externo, mercado interno / mercado externo. Contextualizamos mercado interno, o "conjunto de todos os mercados localizados em um país" e mercado externo, o "conjunto de todos os mercados localizados fora de um país":

A empresa foi uma das poucas do setor imobiliário que não revisou suas metas de lançamentos para 2008 após a chegada da crise financeira internacional ao <mercado interno $>$. De janeiro a setembro, lançou R \$ 550 milhões em valor potencial de vendas (o chamado VGV), equivalente a quase $70 \%$ do programado para o ano, segundo Eduardo Gorayeb, diretor-presidente da empresa. (GM, 02-02-10)

Temos de manter o setor mineral mais ou menos equilibrado com o que se faz no mundo todo. De outro modo, se aumentarmos aqui os royalties desordenadamente, podemos deixar nossas mineradoras sem condições de competir com o <mercado externo>. (ESP, 11-09-09)

Prefixos negativos anexados a uma base formam adjetivos que estabelecem uma relação antonímica com a base desprovida de prefixo. Alguns desses adjetivos integram os termos sintagmáticos variável dependente / variável independente e imposto direto / imposto indireto:

O apetite do Leão não chega a ser nenhuma novidade, embora a carga tributária no Brasil seja extremamente elevada, principalmente se comparada com a baixa qualidade dos serviços públicos financiados pelos tributos. O consultor Clóvis Panzarini, que foi coordenador da Arrecadação Tributária da Secretaria da Fazenda de São Paulo por oito anos, costuma dizer que a carga tributária é 
uma <variável dependente> e que a <variável independente> é o gasto. Seria como a taxa de um condomínio: para diminuí-la, antes é preciso reduzir a despesa. (ESP, 31-12-08)

O único <imposto direto> importante, o imposto sobre a renda, compõe entre $25 \%$ e $30 \%$ da receita total enquanto que os <impostos indiretos> mais importantes chegam à metade da receita. (BACHA, 1989, p. 70)

Outros dois termos da Economia que se opõem pelo prefixação de in- a uma base são demanda elástica e demanda inelástica, que se referem ao conceito econômico de elasticidade, designativo da relação entre a oferta e a procura de um bem em função das alterações verificadas em seu preço. Em função desse conceito, as mercadorias, os bens são vinculados a uma <demanda elástica> ou a uma $<$ demanda inelástica $>$ :

Claudio Felisoni, do Programa de Administração de Varejo, da FIA (Fundação Instituto de Administração), explica que há produtos com a chamada <demanda inelástica>. Isso quer dizer que, mesmo quando o preço do item sobe muito, a quantidade consumida cai pouco. (FSP, 23-08-07)

Se um bem tem uma elasticidade de demanda maior do que 1, então ele tem uma <demanda elástica>. Para elasticidade menor do que 1 denomina-se como < demanda inelástica $>$.

Uma < demanda elástica > é aquela para a qual a quantidade demandada é muito sensível às variações de preço. Se você aumentar o preço em 1\%, a quantidade demandada diminuirá em mais de $1 \%$.

Em geral, a elasticidade de demanda de um bem depende de quantos substitutos esse bem tiver. Se um bem tiver muitos bons substitutos, terá sua curva de demanda muito sensível às variações de preço. No entanto, se não houver bons substitutos para um certo bem, então ele terá uma <demanda inelástica>. (MOREIRA, 1998)

De maneira análoga a adjetivos prefixados por in-, a prefixação de não- a adjetivos contribui para a formação de termos sintagmáticos opostos. Não-, que marca a negação da palavra-base de maneira mais neutra e menos expressiva do que in-, indica também uma complementaridade entre adjetivos opostos, que exemplificamos com bem econômico e bem não econômico:

Utilidade é a aptidão que uma coisa tem para servir à satisfação de necessidades humanas, constituindo, portanto (a utilidade reconhecida como tal), um pressuposto básico para que uma coisa seja um bem. Também os <bens não econômicos> são úteis, pois têm aptidão para o atendimento de necessidades humanas, tanto quanto os <bens econômicos>; essa aptidão deve, naturalmente, ser conhecida por quem utiliza os bens em questão, caso contrário nem sequer se pode falar de bens. O que distingue <bem não econômico $>$ de <bem econômico $>$ é o fato de o atendimento das necessidades humanas não depender da disponibilidade de quantidades concretas do primeiro, mas de quantidades concretas do segundo; assim sendo, o primeiro tem utilidade, ao passo que o segundo, além de utilidade, também tem para nós a importância que denominamos valor. (MENGER, 1983, p. 286)

\section{CONSIDERAÇÕES FINAIS}

Neste breve estudo sobre o papel de alguns adjetivos de caráter opositivo na formação de termos sintagmáticos da Economia, pudemos verificar que a oposição, nesses termos, é marcada sobretudo por adjetivos qualificativos, os únicos que, para Bosque, podem marcá-la.

Deve-se considerar que certos pares opostos, constituídos por adjetivos classificadores, revelam mais diferenças do que propriamente uma oposição nos termos sintagmáticos analisados. É o que se verifica entre os pares vertical / horizontal e interno / externo, que marcam uma diferente localização no espaço; pré-pago / pós-pago, denotadores de uma distinta localização relativa ao tempo; real / 
nominal, reveladores de uma diferença entre o valor que é contratado e o valor de fato disponível; e econômico / não econômico, em que o adjetivo prefixado indica uma complementaridade em relação ao adjetivo sem prefixo. Bosque (op. cit., p. 150) observa que os adjetivos classificadores que recebem um prefixo negativo, diferentemente dos qualificativos que designam um antônimo, implicam uma exclusão. Exemplifica com gramatical / agramatical, legal / ilegal, científico / acientífico.

Com base em nosso estudo, parecem-nos adequadas as considerações de Estopà et al (2002), que reiteram que também os adjetivos qualificativos formam termos nos discursos especializados:

Ao contrário, neste trabalho postulamos que qualquer classe de adjetivo, seja relacional ou qualificativo, é susceptível de representar e comunicar conhecimento especializado. Parece evidente que tanto o adjetivo fenotípico no sintagma nominal marcador fenotípico como o adjetivo grande em célula grande, mensajero em RNA mensajero ou corto no sintagma brazo corto del cromosoma contêm e transmitem conhecimento especializado ${ }^{8}$. (ESTOPÀ et al, 2002)

O caráter opositivo expresso por adjetivos em termos sintagmáticos da terminologia da Economia manifesta-se em outros pares, observados no corpus e que não foram abordados neste estudo. Assim, adjetivos como aberto / fechado, ordinário /preferencial, positivo / negativo, entre outros, que manifestam oposição em termos sintagmáticos a exemplo de economia aberta /, economia fechada, ação ordinária / ação preferencial, saldo positivo / saldo negativo, revelam que a polaridade entre adjetivos constituintes de termos sintagmáticos das línguas de especialidade deve ser objeto de outros estudos.

\section{BIBLIOGRAFIA}

ALVES, Ieda Maria. La synonymie en intelligence artificielle. Méta, Montréal, v. 39, n. 4, p. 643650, 1994.

ARAUJO, Mariangela. A elaboração de um Dicionário Terminológico da Economia: aspectos da Sinonímia nos discursos especializados. Tese (Doutorado) - Faculdade de Filosofia, Letras e Ciências Humanas da Universidade de São Paulo, 2007.

BACHA, Edmar. Introdução à macroeconomia: uma perspectiva brasileira. 7 ed. Rio de Janeiro: Campus, 1989.

BENVENISTE, Emile. Problèmes de linguistique générale. v. 2. Paris: Gallimard, 1974.

BOSQUE, Ignacio; DEMONTE, Violeta. Gramática descriptiva de la lengua espanola. v. 1. Sintaxis básica de las clases de palabras. Madrid: Espasa Calpe, 1999.

CABRÉ, Maria Teresa. La terminología. Teoría, metodología, aplicaciones. Trad. castellan de Carles Tebé. Barcelona: Editorial Antártida / Empúries, 1993.

CHIANG, A. C. Matemática para economistas. São Paulo: Ed. McGraw-Hill / EDUSP, 1982.

CONTENTE, Madalena. Terminocriatividade, sinonímia e equivalência interlinguística em Medicina. Lisboa: Colibri, 2008.

FERGUSON, C. E. Microeconomia. 18 ed. Tradução do inglês de Almir Guilherme. Barbassa e Antônio Pessoa Brandão. Rio de Janeiro: Forense Universitária, 1994.

\footnotetext{
${ }^{8}$ Por el contrario, en este trabajo postulamos que cualquier clase de adjetivo, sea relacional o calificativo, es susceptible de representar y comunicar conocimiento especializado. Parece evidente que tanto el adjetivo fenotípico en el sintagma nominal marcador fenotípico como el adjetivo grande en célula grande, mensajero en RNA mensajero o corto en el sintagma brazo corto del cromosoma contienen y aportan conocimiento especializado.
} 
FRADIN, Bernard. Adjectifs relationnels et morphologie. In : FRADIN, Bernard (dir.). La raison morphologique. Hommage à la mémoire de Danielle Corbin. Amsterdam / Philadelphia: John Benjamins Company, p. 69-92, 2008.

GASPARINI, Diógenes. Direito administrativo. 7 ed. São Paulo: Saraiva, 2002.

GECKELER, Horst. Semántica estructural y teoría del campo léxico. Versión espanola de Marcos Martínez Hernández. Madrid: Gredos, 1976.

KOCOUREK, Rotislav. La langue française de la technique et de la science. 2è. éd. Wiesbaden: Brandstetter Verlag, 1991.

LEHMANN, Alise; MARTIN-BERTHET, Françoise. Introduction à la lexicologie. Paris: Dunod, 1998.

LYONS, John. Eléments de sémantique. Traduction de l'anglais de J. Duand. Paris : Larousse, 1978.

MENGER, Carl. Princípios de economia política. São Paulo: Abril Cultural, 1983. (Coleção "Os

Economistas")

NEVES, Maria Helena de Moura. Gramática de usos do português. São Paulo: Editora UNESP, 2000.

NIKLAS-SALMINEN, Aino. La lexicologie. Paris: Armand Colin, 1997.

REY, Alain. Essays on terminology. Amsterdam / Philadelphia: John Benjamins Publishing Company, 1995.

RIANI, Flávio. Economia do setor público. São Paulo: Atlas, 1990.

SIMONSEN, Mário Henrique; CYSNE, Rubens Penha. Macroeconomia. Rio de Janeiro: Ao Livro Técnico, 1989.

SMITH, Adam. A riqueza das nações: investigação sobre sua natureza e suas causas. Tradução do inglês de Luiz João Baraúna. São Paulo: Abril Cultural, 1983. (coleção "Os Economistas")

VARO VARO, Carmen. La antonimia léxica. Madrid: Arco / Libros, 2007.

\section{REFERÊNCIAS ELETRÔNICAS}

ESTOPA, Rosa; LORENTE, Mercè; FOLGUERÀ, Rosa-Anna. El rol de los adjetivos en los textos especializados. Actas RITERM 1988. 2002. Disponível em: http://www.riterm.net/actes/8simposio/rosaEstopa.htm. Arquivo acessado em 20 de fevereiro de 2011.

MAFRA FILHO, Francisco de Salles Almeida. Direito Público e Direito Privado. Disponível em: http://www.robertexto.com/archivo1/direito_pub_priv.htm\#_ftn6. Arquivo acessado em 25 de março de 2011.

MOREIRA, Juarez Nazareno Muniz. Custos e preços como estratégia gerencial em uma empresa de saneamento. Dissertação (Mestrado em Engenharia de Produção) - Universidade Federal de Santa Catarina. Florianópolis, 1998. Disponível em: http://www.eps.ufsc.br/disserta98/moreira/index.html. Arquivo acessado em 20 de fevereiro de 2011.

OI INDENIZARÁ 3,4 milhões de clientes na Bahia. Disponível em: http://www1.folha.uol.com.br Arquivo acessado em 08 de abril de 2011. 